\title{
Quantifying Forest Biomass Carbon Stocks From Space
}

\author{
Pedro Rodríguez-Veiga ${ }^{1,2} \cdot$ James Wheeler $^{1} \cdot$ Valentin Louis $^{1} \cdot$ Kevin Tansey $^{1}$. \\ Heiko Balzter ${ }^{1,2}$
}

Published online: 9 February 2017

(C) The Author(s) 2017. This article is published with open access at Springerlink.com

\begin{abstract}
Purpose of Review This review presents cutting-edge methods and current and forthcoming satellite remote sensing technologies to map aboveground biomass (AGB).

Recent Findings The monitoring of carbon stored in living AGB of forest is of key importance to understand the global carbon cycle and for the functioning of international economic mechanisms aiming to protect and enhance forest carbon stocks. The main challenge of monitoring AGB lies in the difficulty of obtaining field measurements and allometric models in several parts of the world due to geographical remoteness, lack of capacity, data paucity or armed conflicts. Space-borne remote sensing in combination with ground measurements is the most cost-efficient technology to undertake the monitoring of AGB.

Summary These approaches face several challenges: lack of ground data for calibration/validation purposes, signal saturation in high AGB, coverage of the sensor, cloud cover persistence or complex signal retrieval due to topography. New space-borne sensors to be launched in the coming years will allow accurate measurements of AGB in high biomass forests $\left(>200 \mathrm{t} \mathrm{ha}^{-1}\right)$ for the first time across large areas.
\end{abstract}

This article is part of the Topical Collection on Remote Sensing

Pedro Rodríguez-Veiga

pedro.rodriguez@le.ac.uk

1 Department of Geography, Centre for Landscape and Climate Research, University of Leicester, University Road, Leicester LE1 7RH, UK

2 National Centre for Earth Observation (NCEO), University of Leicester, University Road, Leicester LE1 7RH, UK
Keywords Forest biomass · Carbon · In situ data · Optical · $\mathrm{SAR} \cdot \mathrm{LiDAR}$

\section{Introduction}

Forests cover approximately $30 \%$ percent of the global land surface and play a key role in the global carbon cycle. The world's forests store approximately $45 \%$ of terrestrial carbon [1]. Most of this carbon is stored in trees in the form of AGB through the process of photosynthesis. AGB includes all vegetation above the ground (i.e. stems, branches, bark, seeds, flowers and foliage of live plants) and approximately $50 \%$ of its composition is carbon [2]. AGB is usually measured in metric tons of dry matter per hectare (e.g. $\mathrm{tha}^{-1}$ or $\mathrm{Mg} \mathrm{ha}^{-1}$ ) or in metric tons of carbon per hectare (e.g. $\mathrm{C} \mathrm{ha}^{-1}$ or $\mathrm{MgC} \mathrm{ha}^{-1}$ ).

Intergovernmental organisations and international agreements such as the United Nations Framework Convention on Climate Change (UNFCCC) in 1992 and its extension in 1997 with the Kyoto Protocol have recognised the importance of monitoring and reducing the amount of greenhouse gases (GHG) emitted to the atmosphere from anthropogenic activities. During the 21st Conference of Parties of the UNFCCC in 2015, the first comprehensive climate agreement (Paris Agreement) was achieved, for which the parties aim to hold the increase in the global average temperature to below $2{ }^{\circ} \mathrm{C}$ and to pursue efforts to limit the temperature increase to $1.5^{\circ} \mathrm{C}$. Carbon dioxide $\left(\mathrm{CO}_{2}\right)$ is one of the most significant trace gases, which can alter global biogeochemical cycles such as the global carbon cycle. The heating derived from the increase of $\mathrm{CO}_{2}$ in the atmosphere can also produce changes in weather patterns [3]. In most tropical countries, deforestation is the main source of $\mathrm{CO}_{2}$ from terrestrial ecosystems and the second largest anthropogenic source after fossil fuel combustion [4]. 
The global monitoring of forest AGB is essential to understand the carbon cycle and to reduce carbon emissions. However, its amount and spatial distribution is still uncertain due to the difficulties in measuring AGB at the field scale [5]. Remote sensing techniques, especially space-borne sensors, collect data correlated to the spatial distribution of AGB across large regions, nationally and even globally, in a costefficient manner [6, 7]. Aside from a long series of passive optical remote sensors, researchers and practitioners can also use active sensors such as Synthetic Aperture Radar (SAR) and Light Detection and Ranging (LiDAR).

Global and regional biophysical forest parameter maps such as forest area, canopy cover, growing stock volume (GSV), AGB and canopy height can be generated using remote sensing techniques with spatial resolutions in the range of $25 \mathrm{~m}$ to $1 \mathrm{~km}$ (e.g. [8, 9-14, 15••, 16, 17•, 18-21]). However, these approaches face challenges related to the absence of well-distributed in situ data for calibration at scales useful for remote sensing [22] and the limited sensitivity of satellite sensors to AGB [23]. Each satellite sensor has different strengths and weaknesses related to spatial resolution, sensor technology, number of spectral bands, revisit times and cost. In this review, operational and imminent remote sensing technologies with a focus on space-borne sensors are presented together with current state-of-the-art approaches to estimate carbon stocks in forest AGB.

\section{In Situ Data}

AGB is measured accurately and directly by destructive in situ sampling methods. This is a laborious, expensive and impractical approach for large scales [24]. Non-destructive in situ methods such as forest inventories make use of allometric models to predict AGB. Forest inventories are broadly used for AGB monitoring as their accuracy lies between 2 and $20 \%$ [25]. Biophysical parameters like tree height and diameter at breast height $(\mathrm{DBH})$ are commonly measured in forest inventories and related scientific studies and are used to estimate AGB from allometric equations. Some countries have also developed modelling approaches based on forest stand variables such as tree species, site indices and ecological regions to predict AGB across wide areas [26]. Most forest inventories were developed to estimate commercial growing stock volume of stems, neglecting other biomass components like branches and leaves. Biomass expansion factors (BEFs) are used to convert growing stock into non-inventoried tree components. The use of BEFs involves a two-step process, stem volume estimation followed by the application of the expansion factors. Therefore, allometric equations are preferred over BEFs as the calculation is limited to one step, reducing the error propagation in the process.

As the field samples used to create allometric models are delimited to the study area, their applicability is usually restricted to specific species and sites [27-30]. Allometry varies with climatic conditions, vegetation structure, tree species and growth-form of trees [31-33], and therefore different forest biomes and even regions within biomes will show variations in allometry. The selection of appropriate equations is a crucial step when using allometry as a method. An inappropriate choice of allometric model can become the most important error source in the estimation of AGB [34]. These errors are mostly a consequence of using allometric equations outside the diameter range [34] or in a different area [35] from which those equations were developed. The small sample of tree measurements commonly used to generate these models can result in uncertainties ranging from -4 to $+193 \%$ [36]. Important variations obtained in $\mathrm{C}$ stock have been found, with overestimations of up to $93 \%$ when using different biomass allometric equations in the same study area [37].

Several international consortia such as AfriTRON [38], RAINFOR [39], ForestPlots [40] and CTFS-ForestGEO [41] aim to coordinate long-term monitoring of forest plots. They have established permanent sample plot networks across tropical forests using robust protocols for measurements and continuous monitoring of plots and created databases to be used in ecological studies. These plot networks are essential for calibrating and monitoring remote sensing approaches in tropical forest areas.

In temperate and boreal forested areas, there is good availability of forest inventory ground data as well as allometric equations [42]. Unfortunately, these data are unavailable in many developing countries in tropical regions with large areas of natural forests due to the geographical remoteness, lack of capacity, data paucity or armed conflicts. The Congo Basin is a clear example of the scarcity of ground samples. Even though the Congo basin is one of the largest forested areas in the world, only a small number of plots has been measured and few allometric equations have been developed for the forests of this region [43]. As a result, data availability and subsequently allometric models are the key limiting factors for quantifying AGB. Methods based on or assisted by remote sensing technology aiming to estimate forest biomass over large scales (i.e. global, biome and continental levels) should focus on developing methods which can be applied in areas with data availability problems while accounting for regional variability.

\section{Capabilities and Limitations of Earth Observation Data}

Before the introduction of remote sensing technologies, several approaches were used to produce AGB maps. The most well-known, simple and fast is the biome-average approach. The biome-averages are single values of biomass per unit area (e.g. $\mathrm{t} \mathrm{ha}^{-1}$ ). These biome-averages are applied to broad forest types or biomes and have been mostly calculated and updated from analyses of country-level carbon stock data archived by 
the United Nations Food and Agricultural Organization (FAO). Unfortunately, estimates based on national forest inventories from some developing countries are not always reliable. Additionally, the different sampling designs used by those inventories are not taken into consideration when estimating these values, which might lead to large uncertainties and biases. However, the main advantage of using biomeaverages is that the values are readily available at no cost, hence becoming the simplest starting point for a country to assess the relative amount of carbon stocks [4].

Three broad types of remote sensors on board of Earth observation platforms are generally used to map AGB: passive optical, LiDAR and microwave. Each type of sensor has different characteristics which make them suitable for monitoring forest vegetation. Passive sensors use the reflected sunlight emitted by the sun to obtain measurements, while active sensors generate their own signal, which is reflected, refracted or scattered from the Earth's surface before being received by the sensor. The correlation between the signal received by any type of sensor and AGB can present regional variations due to factors such as forest structure, species composition and wood density, allometry, atmospheric effects and vegetation moisture (e.g. $[44,15 \cdot \bullet])$.

\section{Passive Optical}

Vegetation indices estimated through passive optical imagery (e.g. leaf area index, normalised difference vegetation index) are most sensitive to the photosynthetic parts of vegetation [45]. As a result, those indices are also indirectly related to AGB by means of an empirical relationship between foliage and total AGB. The signal from optical sensors is therefore sensitive to variations in canopy structure, and several methods use this relationship to model AGB across the landscape $[4,46]$. This relationship involves a certain amount of error as the AGB of vegetation is mostly composed of nonphotosynthetic parts.

Optical sensors have great advantages for global vegetation monitoring. The incident electromagnetic radiation that is not absorbed or scattered by the atmosphere can be absorbed, transmitted or reflected by the vegetation. The reflected radiation from the targets is measured by the remote sensor. Vegetation causes diffuse reflection due to its roughness and can be easily differentiated from other surfaces due to chlorophyll causing reflectance in the visible green light spectra and strong reflectance in the near-infrared, as well as absorption in the red and blue sections of the visible spectrum [45].

A multispectral sensor usually has between 3 and 10 broad bands, while hyperspectral sensors have hundreds to thousands of narrow bands. Some studies have used a hyperspectral satellite to map AGB over small areas (e.g. $[47,48])$, but this is challenging for large areas due to processing requirements and the reduced number of hyperspectral satellites.

Optical sensors have been operating for a long time and rich data archives are available for studying vegetation dynamics. For example, the Landsat and NOAA AVHRR missions have acquired observations over the last 40 years. Another advantage of optical sensors is that their high to coarse resolution imagery can usually be obtained for free or at low cost. The main shortcoming of optical imagery is cloud cover obscuring the observations of the land surface. This is not crucial in boreal or temperate latitudes, but can be a problem in tropical areas where only a few days in a year are cloud-free. Moreover, as passive sensors, they can only collect meaningful imagery during daylight, which reduces the number of potential revisit times in comparison with active sensors like SAR or LiDAR. Thus, the chances to obtain a cloud-free image are lowered.

Several studies have mapped AGB calibrating the algorithm with field observations and using high to coarse resolution multispectral optical imagery to upscale the measurements over the landscape (e.g. $[49,14,11,50])$. The use of high-resolution sensors is usually restricted to small areas due to acquisition costs, revisiting times and the large volume of data needed to cover extensive areas. Coarse resolution sensors such as MODIS have a 24-h revisiting time in comparison with moderate resolution sensors such as Landsat with a 16day revisiting pass. As a result, coarse resolution optical sensors have more chances to have cloud-free observations. It should be noted that in partly cloudy conditions, there is a chance of cloud contamination in a coarse resolution pixel where a moderate or high-resolution sensor might capture both cloudy and cloud-free pixels over the same area. Multitemporal radiometrically consistent cloud-free datasets can be generated by high and moderate resolution sensors, but it can be technically demanding and time-consuming [49, 51]. The rapid development of high performance computer facilities (HPC) and cloud computing (e.g. Google Earth Engine) currently allows the generation of such datasets at moderate resolutions for large areas $[52,53 \bullet \bullet, 54]$. The revisiting time of moderate resolution sensors is also improving with new operational programmes such as Sentinel-2, which with two satellites operating simultaneously ( $2 \mathrm{~A}$ and $2 \mathrm{~B}$ ), will reduce potential repeat coverage to 5 days between acquisitions over equatorial regions and up to 2 days over regions in higher latitudes.

Most hyperspectral approaches focus on the retrieval of vegetation indices that can be correlated to forest biochemical parameters and leaf area index (LAI) [55-57]. Using Hyperion data, le Maire et al. [58] was able to estimate canopy leaf biomass. However, the poor relationship between stem biomass and vegetation indices has been indicated by some studies $[59,60]$. Nevertheless, the use of hyperspectral data in combination with other sensors can improve AGB estimations as shown by Lucas et al. [61] and Swatantran et al. [60]. Hyperspectral remote sensing has the potential to improve 
biomass mapping by providing information on vegetation health and species composition.

Optical imagery is therefore suitable for forest area mensuration, vegetation health monitoring and forest classification, but presents limited correlation with forest AGB after canopy closure. Estimation of AGB by optical sensors has to deal with a saturation of the signal retrieval at low AGB stocks due to canopy closure [4]. However, recent studies suggest that there is correlation of optical imagery (Landsat, MODIS) to AGB beyond the theoretical saturation, especially in infrared bands $[13,62,63]$ which are sensitive to shadowing and moisture differences.

\section{Light Detection and Ranging—LiDAR}

LiDAR is a technology consisting of active optical sensors which transmit laser pulses to targets in order to measure distances. LiDAR remote sensing systems can be classified according to the platform in which they are mounted (spaceborne, airborne, ground-based or hand-held), the type of returned signal (discrete return or full waveform), the scanning pattern (profiling or imaging) and the footprint size $(<1 \mathrm{~m}$ diameter small footprint, 10-30 m diameter medium footprint and $>50 \mathrm{~m}$ diameter large footprint). A LiDAR footprint is an area illuminated by the laser and from which the waveformreturn signal gives information.

Because LiDAR sensors retrieve canopy height from the distance measurements between the sensor and the target, they are not limited by the same signal saturation for the estimation of AGB as optical and radar sensors, which correlate AGB with spectral reflectance or radar backscatter signals. A high LiDAR point density allows for more ground returns to be obtained through gaps in the canopy. In particular, airborne and ground-based imaging LiDARs provide direct and very accurate measurements of canopy height. However, the use of airborne and terrestrial platforms would be excessively expensive for continental and global scale mapping. The only spaceborne LiDAR sensor to date was the Geoscience Laser Altimeter System (GLAS) instrument aboard the NASA Ice, Cloud and land Elevation Satellite (ICESat). ICESat scanned the globe from 2003 to 2010 following a footprint profiling pattern along the orbit and produced a global coverage of full waveform signal large footprints (approximately $65 \mathrm{~m}$ in diameter). ICESat sampled millions of such footprints every $172 \mathrm{~m}$ along the track. This sensor did not generate images but provided full-wavelength point information that could be used after processing for calibration purposes. Canopy height can be calculated based on the relative time elapsed between the energy reflected from the top of the canopy and the ground (waveforms) [64]. However, GLAS waveforms have problems estimating canopy height over sloped terrain [65].

Several authors have studied LiDAR-derived biophysical canopy metrics to characterise forest vertical structure [12,
66-71]. Allometric models can then be used with those metrics to estimate $\mathrm{AGB}$. AGB estimated using the large-footprint GLAS sensor has been widely used for calibration/validations purposes, especially in areas with poor field data availability. These LiDAR space-borne sensors cannot be used alone to produce wide area AGB mapping, but they are very useful in combination with other Earth Observation datasets (e.g. [13, $15 \bullet \cdot])$. There is no LiDAR satellite in orbit at the present time, but some are in the development stage.

\section{Microwave}

Microwave earth observation sensors use the electromagnetic radiation in the microwave wavelength range to provide information about the planet's land, ocean and atmosphere. Microwave sensors used in forest biomass studies are either passive microwave radiometers which measure the natural microwave emission from earth or active radar altimeters which transmit microwaves and receive a backscattered signal from a surface. However, few studies have explored the use of passive microwave radiometers to estimate forest AGB [72 ••, 73]. The very coarse spatial resolution allowed by these radiometers $(>10 \mathrm{~km})$ makes the calibration and validation of these approaches difficult and only useful for global scale studies.

Most studies use a type of active radar called SAR which is able to acquire high and moderate resolution imagery. SAR is a side-looking active radar system. The backscattered signal contains both an intensity and a phase component. The intensity is a measure of the strength of the returned signal and is affected by geometric and dielectric properties (essentially the moisture content) of the surface. The phase describes the phase angle of the returned radar echo, and it is a combination of hundreds of interactions with individual scattering objects within a target area. Microwave wavelengths allow imaging of the land surface through cloud cover, and with SAR being an active system, images can also be gathered at night. Airborne or space-borne SAR systems follow a side-looking design that uses the Doppler effect of relative motion between the antenna and its target to provide distinctive long-term coherent signal variations to generate much higher resolution imagery than would be possible from a real aperture radar [74].

There are three fundamental physical scattering mechanisms by which a microwave pulse is scattered. These are volume scattering, double bounce and rough surface (or 'Bragg') scattering [75]. Double-bounce scattering occurs when the signal is reflected from two or three orthogonal surfaces with different dielectric constants, directly back to the sensor. This is common from man-made surfaces, such as in urban environments. Naturally occurring surfaces that cause double-bounce backscattering include vertical tree trunks, particularly those in still water as found in mangrove swamps. Volume or canopy scattering is produced from a 
cloud of randomly oriented dipoles [75] typically seen in leaf and branch interactions in forest canopies. Scattering from a rough surface results in Bragg scattering, with the signal being scattered in multiple directions. Scattering from still water results in very low signal intensity, as most of the signal is reflected away from the sensor.

Transmitted radar pulses are polarised electromagnetic waves in either the horizontal $(\mathrm{H})$ or vertical $(\mathrm{V})$ plane, and the returned signal can also be received in either the horizontal or vertical plane. Co-polarised SAR data (VV-vertical transmit/vertical receive-and $\mathrm{HH}$ - horizontal transmit/ horizontal receive) are generally less useful than crosspolarised (HV and VH) SAR data for AGB measurements; a cross-polarised sensor configuration is sensitive to the changes in polarisation produced by scattering elements within a tree canopy [76].

Several SAR satellites are currently operational. Each SAR satellite works within a specific radar frequency band (with a corresponding wavelength), with an X-, C-, S-, L- or P-band sensor listed in order of increasing wavelength. Longer wavelength SARs (i.e. L- and P- band) have a greater ability to penetrate the surface and canopy cover. The signal interacts with objects at the same scale or larger than its wavelength, with smaller objects not affecting the backscatter. As a result, longer wavelength SAR signals pass through leaves and small branches in the upper canopy and offer more information about differences in larger woody material such as stems and large branches [77] making them more suitable for AGB estimation as large branches and stems comprise the highest percentage of AGB in forests. However, smaller antenna size, higher spatial resolution and reduced power consumption have favoured the use of shorter wavelengths from spaceborne SAR systems, which are sensitive to smaller canopy elements such as leaves and small branches.

The sensitivity of L-band SAR backscatter to AGB saturates at around 100-150 $\mathrm{t} \mathrm{ha}^{-1}[78,79]$. However, some authors have found higher saturation values of more than $250 \mathrm{t} \mathrm{ha}^{-1}$ for L-band [80] and even more than $300 \mathrm{t} \mathrm{ha}^{-1}$ when combined with other SAR datasets such as X-band [81]. Nevertheless, there is no current satellite sensor in orbit (neither optical nor radar) that can offer a reasonable relationship between the observations and the high values of AGB often found in tropical areas $\left(>400 \mathrm{t} \mathrm{ha}^{-1}\right)$ [79, 80, 82-85]. A P-band SAR such as the planned BIOMASS mission is needed to retrieve very high AGB [86].

\section{Current Methods to Map AGB}

Most methods to map AGB can be included in two broad types based on the spatial scale of the approach: small to medium scale methods and large scale methods (Table 1). The first type (small-medium) covers from project size scale to countrywide scale. These approaches are not usually restricted by ground data or air- and space-borne image availability, except in some tropical countries. The second type (large scale) includes spatial scales beyond national borders such as continental or biome level (large countries will also be included here). Ground data availability is the main constraint for calibrating and validating these large scale approaches. At this level, the use of airborne data would be impractical and overly costly.

These projects are generally based on a combination of in situ data and satellite sensors with moderate to coarse spatial resolutions ( $25 \mathrm{~m}$ to ca. $55 \mathrm{~km}$ ). A large amount of different remotely sensed datasets are available, ranging from passive optical, to LiDAR and SAR from either air- or space-borne platforms. All these approaches face the limitations of remote sensing imagery to map forest AGB (i.e. ground data paucity, signal saturation, cloud cover, topography). Most methods use a combination of multiple datasets in order to overcome these limitations. Data synergy approaches enable an exploitation of the specific strengths of each sensor. However, AGB data availability to calibrate these methods is still an important constraint, especially at scales beyond the national level.

Methods to map AGB over large spatial scales can also be separated into parametric and non-parametric approaches. Parametric approaches make assumptions on the shape of the distribution of the data, while non-parametric approaches make fewer or no assumptions. The use of parametric models present bigger challenges for upscaling or extrapolating AGB data, as there are no current satellite observations that can be reasonably related to AGB across the whole landscape. Additionally, the assumptions in parametric models of independence and multivariate-normality are often violated [87]. As complex ecological systems like forests show non-linear relationships, autocorrelation and variable interaction across temporal and spatial scales, non-parametric algorithms often outperform parametric ones [88]. Examples of parametric methods are multiple regression analysis (e.g. [13]) or geostatistical methods such as co-kriging (e.g. [89]), whereas the k-nearest neighbour technique (e.g. [90]), random forests $[13,21]$ and neural networks (e.g. [91]) are examples of nonparametric methods.

\section{Small-Medium Mapping Scale}

The methods used to map AGB from small to medium scale are generally calibrated with forest inventory plot data. However, there is an increasing tendency to use airborne LiDAR as calibration data [105, 106, 109-111]. This type of approach relates AGB field observations to airborne LiDAR data, and then calibrates the parameter retrieval from spaceborne sensors using those LiDAR datasets. As mentioned before, the use of airborne data is only feasible at national level or below due to logistic and economic constrains. 


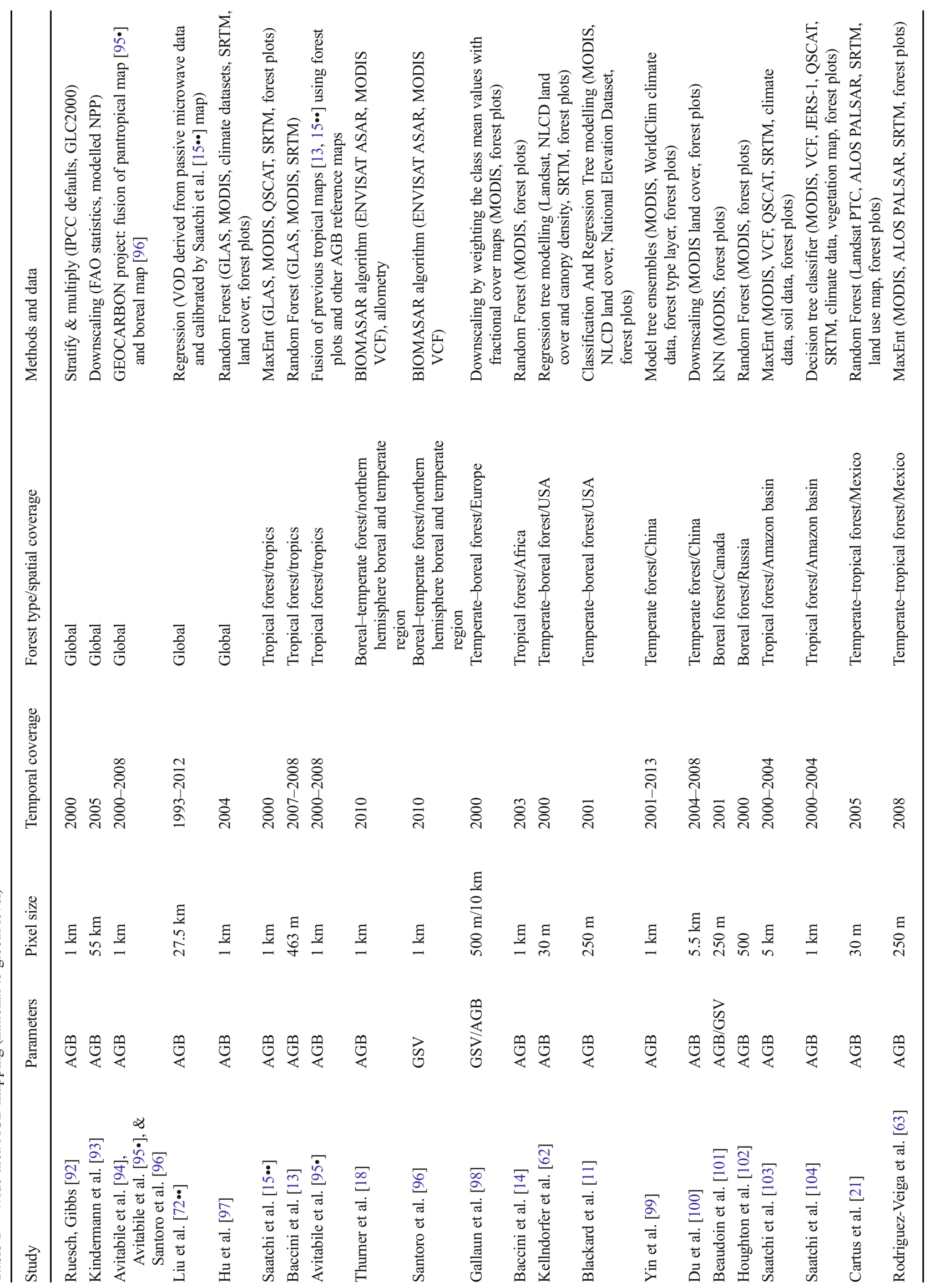




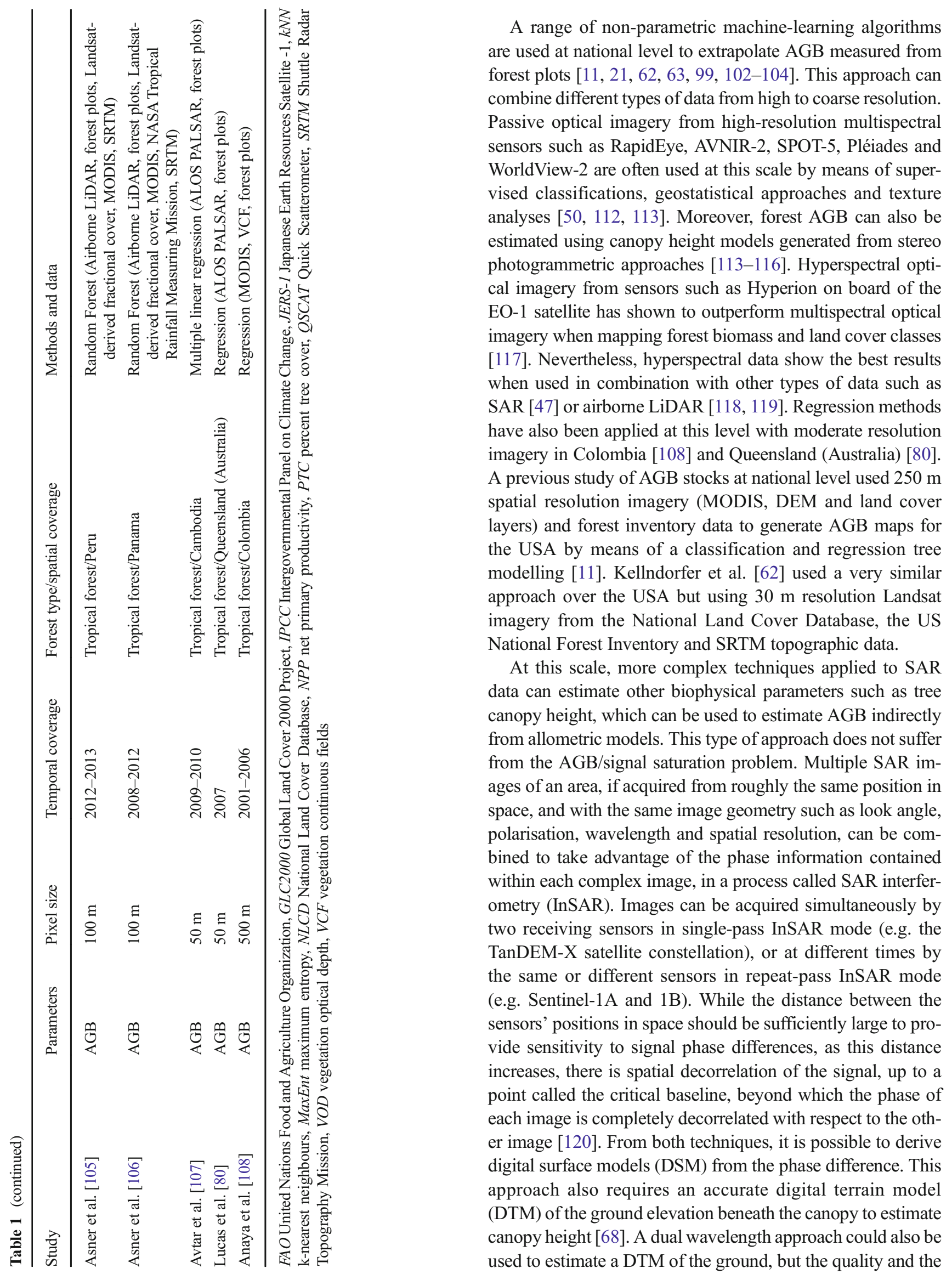


type of DTM will determine the accuracy of the AGB estimations (Fig. 1). The phase correlation between two acquisitions determines the reliability of InSAR measurements and is known as interferometric SAR coherence. For longer wavelengths, lower coherence between repeat-pass image pairs indicates the presence of denser vegetation, as scatter between image acquisitions increases with forest growing stock volume [121].

Polarimetric interferometry (PolInSAR) is another SAR technique which, in contrast to single-polarisation InSAR, does not rely on an external DTM, as it estimates terrain and canopy height from the vertical heights of the scattering phase centres of the different polarimetric scattering mechanisms [122-124]. Different polarisations interact more strongly with different scatterers, such as canopy (HV) and trunk (HH). SAR tomography (TomoSAR) goes beyond the PolInSAR technique by using a set of multiple baselines of interferometric SAR images to generate a $3 \mathrm{D}$ vertical structure of the vegetation canopy based on the variation of backscattering as a function of height $[86,125]$. Most of these techniques are difficult to use over large areas due to the restrictive data requirements. Better availability of SAR sensors allowing higher spatial and temporal resolution acquisitions might circumvent these limitations.

\section{Large Mapping Scale}

At large scales, data availability is the main limiting factor of AGB mapping approaches. Additionally, estimating AGB for very different ecosystems, such as tropical and boreal forest, using the same method can be very challenging due to the variations in forest structure, species composition, wood density, allometry, atmospheric effects and vegetation moisture.

Two recent map products $\left[13,15 \bullet^{\bullet}\right]$ established a benchmark in the synergistic use of different earth observation datasets to map AGB across the whole tropical biome. These studies use AGB estimated from millions of GLAS footprints to calibrate their methods. The approach by Baccini et al. [13] relates GLAS waveforms to AGB using a model calibrated by ground plots directly located under the GLAS footprints, while Saatchi et al. [15••] use three plot-level continental allometric models derived from ground data to relate GLAS-derived Lorey's height $\left(H_{\mathrm{L}}\right)$ to AGB. The use of a model for each continent might better explain the allometric regional variability than a single model, but might still introduce a great amount of uncertainty when applied to different forest biomes. These studies used machine-learning algorithms such as random forest [87] and MaxEnt [126, 127] for upscaling of the AGB across wide areas, to produce $463 \mathrm{~m}$ and $1 \mathrm{~km}$ resolution maps, respectively. Saatchi et al. [15••] reported a relative error of approximately $30 \%$ across the three continents, while Baccini et al. [13] reported similar figures in terms of root mean square error (RMSE) (38-50 tha $\left.{ }^{-1}\right)$. One of the most innovative features of the Saatchi et al. [15•*] study was the possibility of mapping the uncertainty of the AGB estimation on a pixelby-pixel basis. Both approaches use MODIS spectral bands and the SRTM digital elevation model as predictor variables, and in the case of Saatchi et al. [15••] also Quick Scatterometer data (QSCAT). These methods aim to take advantage of the full potential of the information contained in each input band, but none of these bands on its own can fully explain the variability of AGB across the landscape.

These two products provide very different results on the amount and spatial distribution of AGB at finer resolutions [128] (Table 2 and Fig. 1). Differences when compared to in situ AGB data or to local AGB maps have also been found $[129,130]$ but can be partially explained by the allometric models used to estimate AGB, different ground and remote sensing data, modelling techniques, pixel sizes and temporal coverage. Mitchard et al. [129] found that these maps do not agree with the spatial distribution of AGB in permanent Amazon field plots and that the uncertainties quantified in a comparison with 413 ground plots far exceed those reported by the studies. Saatchi et al. [131] responded to Mitchard et al. [129] arguing that, aside from methodological flaws in the interpolation approach, using 413 plots from different periods
Fig. 1 Vegetation carbon content at Monks Wood National Nature Reserve derived from the canopy height models from a LIDAR DSM and LIDAR DTM, b XVV InSAR DSM and LIDAR DTM, c XVV InSAR DSM and smoothed interpolated LHH InSAR DTM (dual wavelength approach). Warmer colours indicate higher carbon content (range from 5 to $400 \mathrm{t} \mathrm{C} \mathrm{ha}^{-1}$ ). Adapted with permission from Balzter et al. [68]
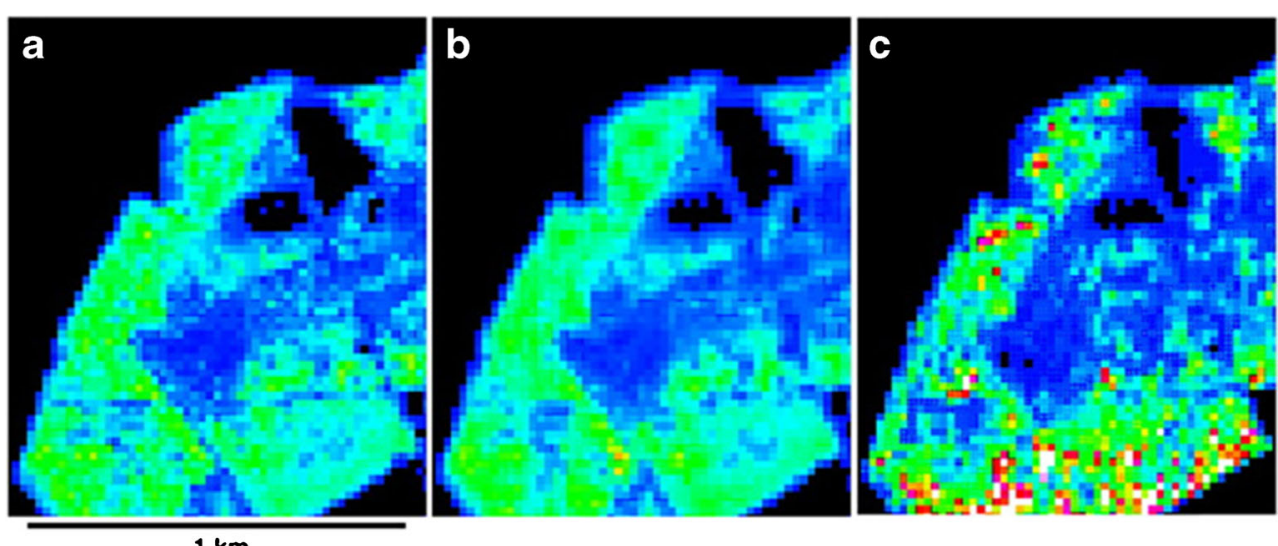

$1 \mathrm{~km}$ 
Table 2 Total AGB stocks (Pg) by continent in the tropical biome

\begin{tabular}{lllllr}
\hline Continent & $\begin{array}{l}\text { Saatchi et } \\
\text { al. [15••] }(\mathrm{Pg})\end{array}$ & $\begin{array}{l}\text { Baccini et } \\
\text { al. [13] (Pg) }\end{array}$ & $\begin{array}{l}\text { Avitabile et } \\
\text { al. [95•] (Pg) }\end{array}$ & $\begin{array}{l}\text { Liu et al. } \\
{[72 \bullet \bullet](P g)}\end{array}$ & $\begin{array}{l}\text { Hu et al. } \\
{[97](\mathrm{Pg})}\end{array}$ \\
\hline Africa & 113 & 129 & 96 & 126 & 96 \\
America & 193 & 234 & 186 & 223 & 257 \\
Asia & 107 & 93 & 92 & 79 & 116 \\
Tropics & 413 & 457 & 375 & 428 & 469 \\
\hline
\end{tabular}

Comparison of AGB stocks for continental regions based on the coverage of the Baccini et al. [13] map which has the most limited coverage of the maps between 1956 and 2013 only represent 404.6 ha out of 650 million ha of forest in the Amazon and without a rigorously designed and extensive in situ forest inventory strategy are not representative of the AGB trends in the region. Nonetheless, the consistency of both products at coarser scales suggests that realistic estimates of carbon stocks can be produced over large regions.

The two pantropical carbon maps were fused using a methodology that incorporated research field observations, forest inventory plots and other high-resolution biomass maps [95•]. The method was based on bias-removal and weighted-averaging of the regional maps, and resulted in a pantropical map with a 15$21 \%$ lower RMSE than that of the input maps, and lower bias (mean bias $5 \mathrm{t} \mathrm{ha}^{-1}$ vs. 21 and $28 \mathrm{tha}^{-1}$ for the input maps).

Boreal and temperate forest GSV was mapped at $100 \mathrm{~m}$ and $1 \mathrm{~km}$ spatial resolution using hyper-temporal data series of Envisat ASAR ScanSAR backscatter imagery by means of a parametric semi-empirical model called BIOMASAR [17•]. The major advantage of this parametric semi-empirical approach is that the algorithm does not rely on training data. The high uncertainty of the $100 \mathrm{~m}$ resolution map (average $70 \%$ relative error) was considerably reduced (average $43 \%$ ) when aggregating to coarser pixels of $1 \mathrm{~km}$ resolution. The applicability of this C-band SAR algorithm to tropical areas with much higher AGB density is unclear, but adapting the algorithm to use larger SAR wavelengths such as L-band could potentially overcome this problem. Thurner et al. [18] used the GSV estimated from this product in combination with specific wood density information and allometric relationships between biomass compartments (stem, branches, foliage and roots) to produce a $\mathrm{C}$ stock map for the boreal and temperate forests at ca. $1 \mathrm{~km}$ spatial resolution.

GSV at $500 \mathrm{~m}$ and AGB at $10 \mathrm{~km}$ were also mapped continentally for the whole of the European Union [98] using a downscaling approach that weighted the land cover class mean GSV values extracted from forest inventories by fractional cover maps developed using MODIS data. An Africawide map was also produced at $1 \mathrm{~km}$ resolution by extrapolating data from forest plots by means of MODIS imagery and a random forest algorithm, producing a RMSE of $50.5 \mathrm{t} \mathrm{ha}^{-1}$.

Early efforts to monitor forests at global level led to the Forest Resource Assessments (FRAs) by the United Nations
(UN) Food and Agriculture Organization (FAO). These assessments are based on the analysis of forest inventory information supplied by each country and supported by expert judgements, remote sensing and statistical modelling [132, 133]. National Forest inventories are the most widely used method for in situ forest monitoring due to its historic roots in national forestry administrations, its accuracy and low technical requirements. The approach consists of sample-based statistical methods, sometimes in combination with remote sensing and aerial imagery. In developing countries where the labour cost is low, the use of forest inventories could be a relatively cost-effective approach. However, it was not until 2000 that a single technical definition for forest was used ( $>10 \%$ crown cover). Changes in baseline information, inconsistent methods and definitions through the different FRAs make their comparison difficult [134]. Several authors have questioned the country-level estimates of forest carbon stocks reported by the FRAs due to inadequate sampling for the national scale, inconsistent methods and in some tropical countries figures that were not based on actual measurements $[4,135,136]$. These assessments however do not generate spatial estimations of AGB, but national level statistics on forest cover, forest state (e.g. GSV), forest services and non-wood forest products.

First global AGB maps were not based on remote sensing imagery but on downscaling of FAO forest inventory statistics using annual net primary production NPP model outputs [93] and on the assignment of IPCC default AGB averages (estimated from FAO data) to GLC2000 [137] land cover classes [92]. Following the same fusion approach as Avitabile et al. [95•], a global map of AGB was generated for the GEOCARBON project [94], fusing the boreal map from Santoro et al. [96] and the pantropical map from Avitabile et al. [95•] at ca. $1 \mathrm{~km}$ pixel size. $\mathrm{Hu}$ et al. [97] recently published a global AGB map based on a combination of GLAS footprints, forest inventory data, optical imagery, climate data and land cover layers by means of a random forest approach. The AGB estimations of $\mathrm{Hu}$ et al. [97] seem to be much higher than previous global and pantropical maps (Fig. 2)

Vegetation optical depth (VOD) from Earth's passive microwave radiation acquired by the Advanced Microwave Scanning Radiometer (AMSR-E) sensor was used to map AGB globally over a long time period (1993-2012) [72••]. 


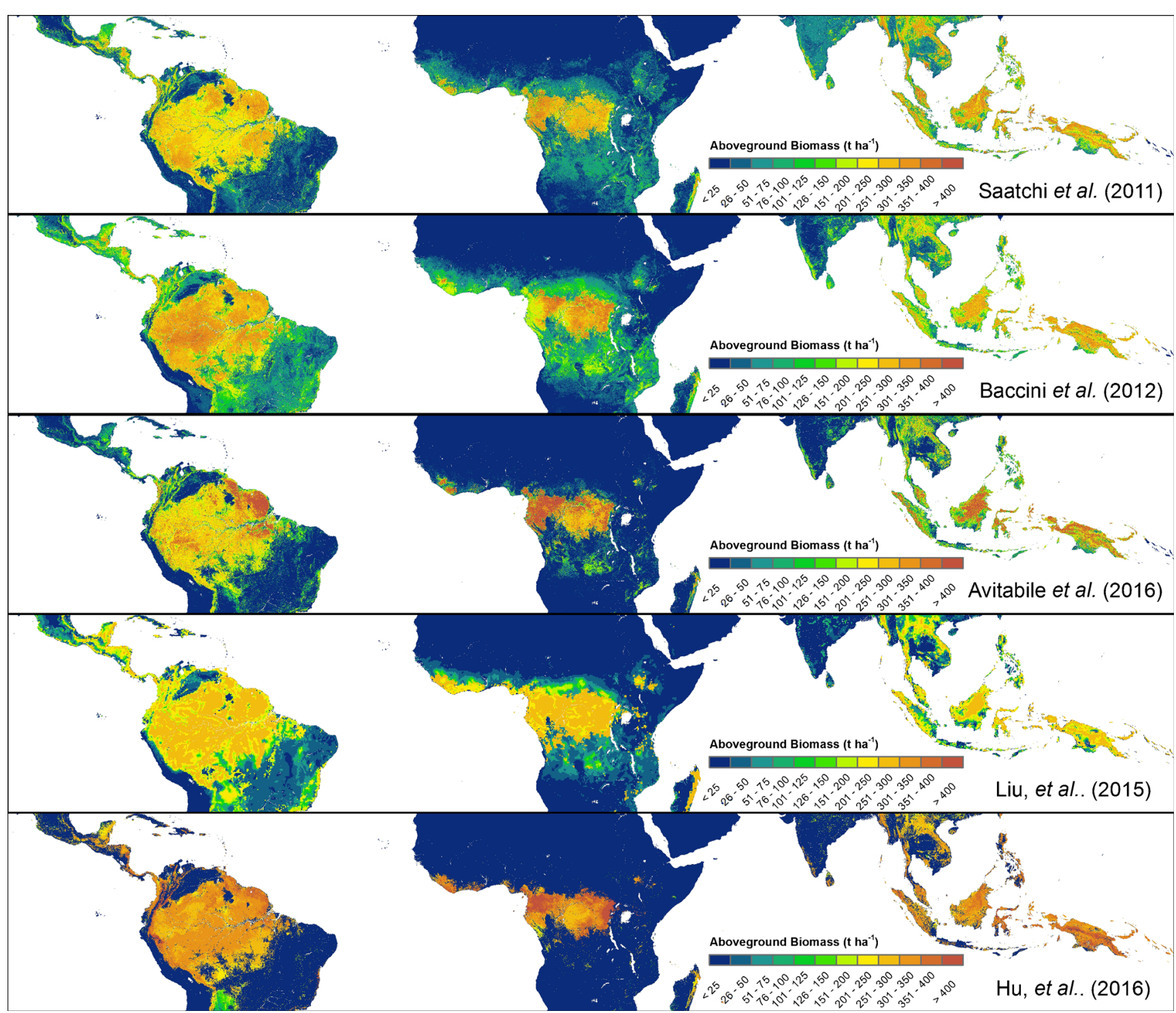

Fig. 2 Pantropical carbon maps from Saatchi et al. [15••], Baccini et al. [13] and the fused version from Avitabile et al. [95•]. Global maps from Hu et al. [97] and Liu et al. [72••] are also displayed over the pantropical area

The main disadvantage from this approach comes from the low energy of this radiation which only allows coarse resolutions $(27.5 \mathrm{~km}$ pixel in this study). Additionally, there is no ground data available at these spatial scales that would allow calibration of such pixel sizes. In Liu et al.'s [72••] study, aggregated pixels from the Saatchi et al. [15••] map were used for calibration. As a result, any of the uncertainties from the Saatchi et al. [15••] map will propagate into this new product. Similar approaches are being investigated using ESA's Soil Moisture and Ocean Salinity (SMOS) mission [73, 138].

Carbon trends estimated by Liu et al. [72••] are comparable in boreal and temperate areas to trends reported by Pan et al. [139••] calculated using ground observations for the period 2000-2007. However, both studies disagree in their estimations for tropical areas where the loss of AGB is much larger in the study of Liu et al. [72••] (Fig. 3). Pantropical carbon maps have divergent AGB estimations in comparison to ground data [129] being significantly larger in some regions [63]. This might explain the larger AGB loss found in tropical regions by Liu et al. [72••] in comparison to Pan et al. [139••], as the Saatchi et al. [15••] map was used as calibration of the approach.

Pantropical AGB maps $[13,15 \cdot \bullet]$ can differ in their estimations and might not agree with ground observations [63, 128-130]. Understanding the reasons behind these differences is crucial for improving contemporary retrieval methods. Initiatives such as the Biomass Geo-Wiki [140] use a crowdsourcing approach to compare and validate forest AGB products to address tasks related to gap analysis, cross-product validation, possible harmonisation and hybrid product development. The site allows the analysis of the pantropical carbon maps $[13,15 \bullet, 95 \bullet]$ and other continental and national level products. A similar initiative, based on the study by Mitchard 
Fig. 3 Comparison of AGB change in the period 2000-2007 between Pan et al. [139••] and Liu et al. $[72 \bullet \bullet]$

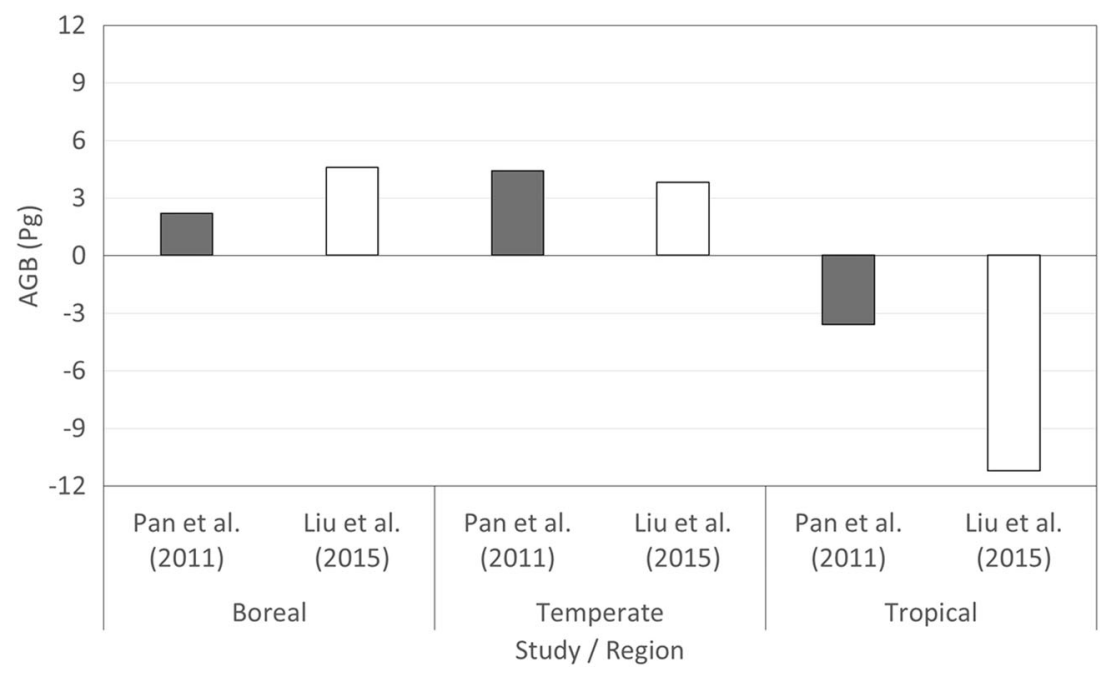

et al. [128] which compared the tropical carbon maps [13, 15••] led to the development of the website "Comparing Global Carbon Maps" [141]. This site allows the interactive comparison between both maps, as well as between other carbon maps provided by different authors. The Global Forest Watch (GFW) platform has also been recently developed with the aim to improve forest information from remote sensing and ground observations [142]. The platform provides information on forest change, land cover (including AGB), land use, conservation and human interactions. The main dataset is the 12 years forest cover loss and gain product developed by Hansen et al. [53••] and a new AGB map at $30 \mathrm{~m}$ resolution based on the methodology used by Baccini et al. [13].

\section{Future Scenario}

At least three space-borne LiDAR sensors should be operational in the near future, inspired by the heritage of the ICESat satellite (GLAS sensor), which was widely used as a calibration/validation dataset for AGB mapping at biome and continental levels (Table 3). ICESat-2 will be launched in 2017 with the Advanced Topographic Laser Altimeter System (ATLAS) on board. The main objective of this satellite, as with the previous ICESat, is monitoring ice sheet elevation and sea ice thickness. The mission also has a secondary objective to estimate ground surface height, canopy height and canopy cover. However, it is not clear whether the ATLAS sensor will be suitable to estimate canopy height and AGB on forest areas due to concerns on the noise level of the discrete return photon-counting system [143, 144]. Additionally, AGB estimation by ATLAS in sparse forests such as the boreal taiga-tundras and savannas will be challenging due to the low sampling rate, the sole use of the green wavelength and the low sensitivity of the sensor to discern differences in AGB at $10 \mathrm{t} \mathrm{ha}^{-1}$ intervals [144, 145].
Two other LiDAR sensors specifically designed for forest structure characterisation will be attached to the International Space Station (ISS). The Global Ecosystem Dynamics Investigation LiDAR (GEDI) mission on board the ISS should be operational in 2018 [146]. The GEDI instrument will be composed of three laser transmitters that will acquire 14 parallel tracks of $25 \mathrm{~m}$ footprints [147]. The main objective of the GEDI mission is to quantify the spatial and temporal distribution of AGB carbon. The Multifootprint Observation LiDAR and Imager (MOLI) should be operative in 2019 and will also be attached to the ISS [148]. This sensor will have two aligned nadir-viewing LiDARs to capture multi-footprints and a multiband imager (green, red and near-infrared) with $5 \mathrm{~m}$ resolution. The aim of this mission is to determine canopy height more precisely by the synergy between LiDAR and a high-resolution optical sensor able to provide information on crown size and approximate height. Unfortunately, GEDI and MOLI will not be able to obtain footprints from boreal forests (30\% of world's forest) due to the orbital characteristics of the ISS.

The forthcoming LiDAR sensors could be a game changer in the coming years, providing millions of LiDAR footprints to potentially characterise forest structure and AGB and could be used for calibration and validation of methods based on optical and SAR imagery. LiDAR profilers will certainly generate key datasets for mapping AGB at large scales and be a realistic solution for the AGB data availability problem. Approaches such as the ones presented by Saatchi et al. [15••] and Baccini et al. [13] will also be feasible to replicate. These approaches are based on non-parametric algorithmic methods (i.e. MaxEnt and Random Forest), which are often more suitable to model complex ecosystems such as forests $[15 \bullet \cdot]$. The drawback of these approaches is the lack of calibration/validation data in several parts of the world. Semi-empirical methods such as the BIOMASAR algorithm [17•], which do not require ground data for algorithm 
calibration, would be very promising if adapted to longer SAR wavelengths such as L-and P-band.

There is a wide range of optical multispectral sensors relevant for monitoring vegetation (e.g. Landsat $7 \mathrm{ETM}+$, Landsat 8 OLI, Sentinel-2A/3A, SPOT 6/7, MODIS and PROBA-V), as this has traditionally been the most widespread technology used by Earth Observation Satellites. In the period between 2017 and 2021, we will see a continuation of programmes such as Landsat and Sentinel with the new Landsat 9 and additional Sentinel satellites (2B, 2C, 3B and 3C) being launched (Table 3). All these new sensors ensure the continuity of the optical archive, which started with the Landsat programme more than 40 years ago, as well as the large scale and coarse spatial resolution sensors AVHRR, MERIS and MODIS. The Sentinel-2 satellites provide the highest resolution $(10 \mathrm{~m})$ operational free-of-charge optical imagery currently available, improving over the $30 \mathrm{~m}$ resolution imagery provided by Landsat satellites. Hyperspectral technology is still underrepresented on satellite platforms but planned satellites such as the EnMAP (2018) and PRISMA are very promising.

Governments and space agencies are currently starting to recognise the advantages of SAR sensors for a wide range of applications. There are more SAR instruments in space than ever before, and numbers are to increase steadily in the coming years (Table 3). Radar has several characteristics that are an advantage for forest monitoring, including cloud penetration (useful in very cloudy areas, such as over most tropical forests) and correlating strongly with AGB at long wavelengths such as L-band. Current short-wavelength X-band $(2.4-3.8 \mathrm{~cm})$ SAR satellites such as the TerraSAR-X and COSMO-SkyMed constellations will be complemented by the Paz Satellite (2017) and the second generation of COSMO-SkyMed (2018-2019). C-band SAR (3.8-7.5 cm) satellite programmes such as Radarsat and Sentinel-1A/1B will also continue with new additions in future years with the new Radarsat constellation (2018) and Sentinel 1C (2021). The only S-band satellite (Huanjing 1C) will have a continuation with NovaSAR-S (2017). Larger wavelengths such as L-band $(15-30 \mathrm{~cm})$ ALOS-2 will have continuation with the SAOCOM 1A (2017), 1B (2018) and SAOCOM Companion Satellite (CS) Mission (2018). SAOCOM 1A/ $1 \mathrm{~B}$ will fly in constellation with COSMO-SkyMed forming the SIASGE L+X-band SAR System. SAOCOM-CS is a receive-only dual-pol sensor platform designed to fly in formation with SAOCOM-1A/1B. This orbital combination will allow techniques such as SAR polarimetry, polarimetric SAR interferometry and SAR tomography. The NASA-ISRO Synthetic Aperture Radar (NISAR) mission (2021) will be the first dual-frequency SAR satellite (L- and S- band).

A larger wavelength than L-band is however better suited to estimating high AGB levels, and the BIOMASS P-band $(30-100 \mathrm{~cm})$ sensor is therefore very promising [86]. The BIOMASS mission is due to be launched in 2021. This 
mission by the European Space Agency (ESA) has the following accuracy requirements at $200 \mathrm{~m}$ pixel level: a RMSE of $\pm 10 \mathrm{tha}^{-1}$ for AGB below $50 \mathrm{tha}^{-1}$ and a relative error of $\pm 20 \%$ for AGB above $50 \mathrm{tha}^{-1}$. If successful, this will be the first space-borne P-band SAR and will be sensitive to high AGB (Fig. 4). The mission however is restricted to measure outside of the US Space Objects Tracking Radar (SOTR) area [151]. This means that the sensor will have to be turned off over North America, Central America and Europe. Nevertheless, most AGB rich tropical forests worldwide will still be surveyed by the BIOMASS satellite.

Optical and SAR imagery sense the vegetation by means of different physical processes which have different sensitivity to AGB. SAR imagery has a higher AGB saturation point than optical imagery according to the literature [79, 80, 82-85], but recent studies have also found that optical infrared imagery might have correlation to AGB beyond its theoretical saturation point $[13,62]$. As the theoretical saturation point of current SAR L-band imagery lies around $150 \mathrm{t} \mathrm{ha}^{-1}$ [78, 152], we will have to wait for the P-band BIOMASS mission to be able to

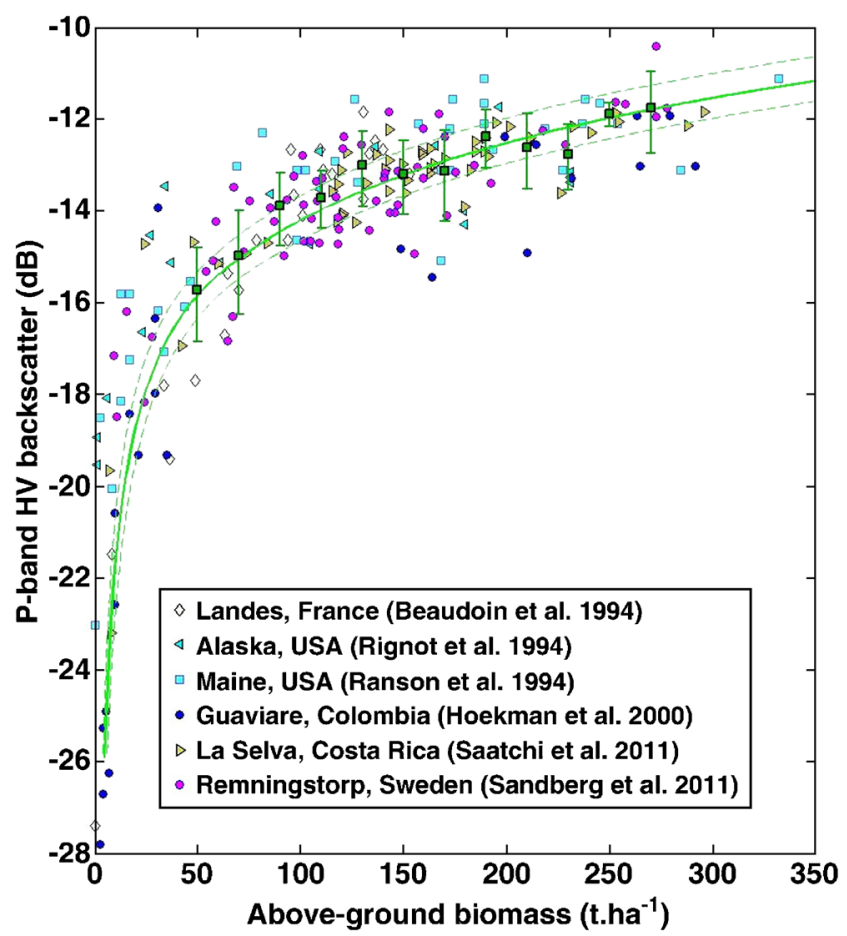

Fig. 4 P-band HV backscattering coefficient plotted against aboveground biomass for experiments conducted at six different forest sites. The green squares with error bars indicate the mean and standard deviation of the data points within intervals of $\pm 10 \mathrm{t} \mathrm{ha}^{-1}$ centred on values of biomass spaced by $20 \mathrm{t} \mathrm{ha}^{-1}$, beginning from $50 \mathrm{t} \mathrm{ha}^{-1}$ and running out to $270 \mathrm{t} \mathrm{ha}^{-1}$. The solid green line is a regression curve derived from the combined data reported in the publications prior to 2009. The dashed curves are obtained by replacing the biomass value, $\mathrm{B}$, by $0.8 \times \mathrm{B}$ and $1.2 \times \mathrm{B}$ in the regression equation. Reprinted with permission from Le Toan et al. [86] estimate AGB in high biomass regions (over $200 \mathrm{t} \mathrm{ha}^{-1}$ ). However, none of these sensors can be used alone for AGB estimation globally, either because of limitations in signal saturation, coverage, cloud cover persistence or complex signal retrieval due to topography. The use of data synergy approaches makes it possible to exploit the specific strengths of each sensor. Aiming to better characterise and to reduce uncertainties of AGB estimates by identifying limitations of current datasets and methods to estimate AGB and by developing innovative synergistic mapping approaches; ESA established the Data User Element (DUE) GlobBiomass project [153]. The project works in five regions covering boreal, temperate and tropical forest biomes (Mexico, South Africa, Poland, Sweden and Kalimantan) developing map products for the years 2005, 2010 and 2015 [154] and a global map for the year 2010 [155]. The use of these approaches might allow the generation of an AGB baseline before the BIOMASS mission is in orbit.

\section{Conclusion}

This review has shown current methods to estimate AGB using passive and active space-borne remote sensing technology. Most approaches are limited by ground data availability for calibration/validation, signal saturation with AGB, coverage of the sensor, cloud cover persistence or complex signal retrieval due to topography. This highlights the importance of synergistic approaches which aim to overcome these limitations by exploiting the advantages of several sensors. Several promising techniques used at small scale (e.g. PolInSAR, TomoSAR) have not been tested yet at larger scales due to complexity and data requirements. However, this might change due to the imminent availability of high spatial and temporal resolution datasets being acquired by new sensors. The new generation of optical sensors (e.g. Sentinel-2), LiDAR profilers (ICESat-2, GEDI and MOLI) and SAR sensors (e.g. BIOMASS, SAOCOM and Sentinel-1) will allow the estimation of AGB to a spatial and temporal resolution never seen before and with an unprecedented accuracy.

Acknowledgments P. Rodriguez-Veiga and H. Balzter were supported by the UK's National Centre for Earth Observation (NCEO). P. Rodriguez-Veiga was also supported by the ESA DUE GlobBiomass project - ITT AO/1-7822/14/I-NB and H. Balzter by the Royal Society Wolfson Research Merit Award, 2011/R3.

Open Access This article is distributed under the terms of the Creative Commons Attribution 4.0 International License (http:// creativecommons.org/licenses/by/4.0/), which permits unrestricted use, distribution, and reproduction in any medium, provided you give appropriate credit to the original author(s) and the source, provide a link to the Creative Commons license, and indicate if changes were made. 


\section{References}

Papers of particular interest, published recently, have been highlighted as:

- Of importance

- Of major importance

1. Bonan GB. Forests and climate change: forcings, feedbacks, and the climate benefits of forests. Science. 2008;320(5882):1444-9. doi:10.1126/science.1155121.

2. IPCC. IPCC guidelines for National Greenhouse Gas Inventories. Japan: Prepared by the National Greenhouse Gas Inventories Programme: IGES; 2006.

3. IPCC. Climate Change: Synthesis Report 2014. Contribution of Working Groups I, II and III to the Fifth Assessment Report of the Intergovernmental Panel on Climate Change [Core writting team R.K. Pachauri and L.A. Meyer (eds.)]. Geneva, Switzerland: IPCC2014 2014. Report No.: 9291691437.

4. Gibbs HK, Brown S, Niles JO, Foley JA. Monitoring and estimating tropical forest carbon stocks: making REDD a reality. Environ Res Lett. 2007;2(4):045023. doi:10.1088/1748-9326/2/4/045023.

5. ESA. 2012 BIOMASS Report for mission selection May 2012. Report No.: SP-1324/1.

6. Brewer CK.. Forest carbon monitoring: A review of selected remote sensing and carbon measurement tools for REDD+. 2012.

7. Bottcher H, Eisbrenner K, Fritz S, Kindermann G, Kraxner F, McCallum I, et al. An assessment of monitoring requirements and costs of 'Reduced emissions from deforestation and Degradation'. Carbon balance and management. 2009;4(1):7.

8. Hansen MC, DeFries RS, Townshend JRG, Carroll M, Dimiceli C, Sohlberg RA. Global percent tree cover at a spatial resolution of 500 meters: first results of the MODIS vegetation continuous fields algorithm. Earth Interactions. 2003;7(10):1-15. doi:10. 1175/1087-3562(2003)007<0001:gptcaa>2.0.co;2.

9. Hame T, Kilpi J, Ahola HA, Rauste Y, Antropov O, Rautiainen M, et al. Improved mapping of tropical forests with optical and SAR imagery, part I: forest cover and accuracy assessment using multiresolution data. IEEE Journal of Selected Topics in Applied Earth Observations and Remote Sensing. 2013;6(1):74-91. doi:10. 1109/JSTARS.2013.2241019.

10. Hame T, Rauste Y, Antropov O, Ahola HA, Kilpi J. Improved mapping of tropical forests with optical and SAR imagery, part II: above ground biomass estimation. IEEE Journal of Selected Topics in Applied Earth Observations and Remote Sensing. 2013;6(1):92-101. doi:10.1109/JSTARS.2013.2241020.

11. Blackard JA, Finco MV, Helmer EH, Holden GR, Hoppus ML, Jacobs DM, et al. Mapping U.S. forest biomass using nationwide forest inventory data and moderate resolution information. Remote Sens Environ. 2008;112(4):1658-77. doi:10.1016/j.rse. 2007.08.021.

12. Lefsky MA. A global forest canopy height map from the Moderate Resolution Imaging Spectroradiometer and the Geoscience Laser Altimeter System. Geophys Res Lett. 2010;37:L15401. doi:10. 1029/2010gl043622.

13. Baccini A, Goetz SJ, Walker WS, Laporte NT, Sun M, SullaMenashe D, et al. Estimated carbon dioxide emissions from tropical deforestation improved by carbon-density maps. Nature Clim Change. 2012;2(3):182-5. http://www.nature.com/nclimate/ journal/vaop/ncurrent/abs/nclimate1354.html\#supplementaryinformation

14. Baccini A, Laporte N, Goetz SJ, Sun M, Dong H. A first map of tropical Africa's above-ground biomass derived from satellite imagery. Environ Res Lett. 2008;3(4) doi:10.1088/1748-9326/3/4/ 045011 .
15.• Saatchi SS, Harris NL, Brown S, Lefsky M, Mitchard ETA, Salas $\mathrm{W}$, et al. Benchmark map of forest carbon stocks in tropical regions across three continents. Proc Natl Acad Sci. 2011;108(24): 9899-904. doi:10.1073/pnas.1019576108. This paper presents a benchmark synergistic approach to map for the first time forest carbon and its associated uncertainty at pixel level over the whole pantropical region.

16. Simard M, Pinto N, Fisher JB, Baccini A. Mapping forest canopy height globally with spaceborne lidar. J Geophys Res. 2011;116(G04021):G04021. doi:10.1029/2011JG001708.

17. Santoro M, Beer C, Cartus O, Schmullius C, Shvidenko A, McCallum I, et al. Retrieval of growing stock volume in boreal forest using hyper-temporal series of Envisat ASAR ScanSAR backscatter measurements. Remote Sens Environ. 2011;115(2): 490-507. doi:10.1016/j.rse.2010.09.018. This paper presents a semi-empirical model (BIOMASAR) for estimation of GSV using hypertemporal C-band SAR which does not need ground data for calibration.

18. Thurner M, Beer C, Santoro M, Carvalhais N, Wutzler T, Schepaschenko D, et al. Carbon stock and density of northern boreal and temperate forests. Glob Ecol Biogeogr. 2014;23(3): 297-310. doi:10.1111/geb.12125.

19. Asner G, Mascaro J, Muller-Landau H, Vieilledent G, Vaudry R, Rasamoelina M, et al. A universal airborne LiDAR approach for tropical forest carbon mapping. Oecologia. 2012;168(4):1147-60. doi:10.1007/s00442-011-2165-z.

20. Avitabile V, Herold M, Henry M, Schmullius C. Mapping biomass with remote sensing: a comparison of methods for the case study of Uganda. Carbon balance and management. 2011;6(1):7.

21. Cartus O, Kellndorfer J, Walker W, Franco C, Bishop J, Santos L, et al. A National Detailed Map of Forest Aboveground Carbon Stocks in Mexico. Remote Sens. 2014;6(6):5559-88.

22. Houghton R, Hall F, Goetz SJ. Importance of biomass in the global carbon cycle. Journal of Geophysical Research: Biogeosciences (2005-2012). 2009;114(G2).

23. Patrício MdS, Monteiro MdL, Tomé M. Biomass equations for Castanea sativa high forest in the Northwest of Portugal. Acta Horticulturae. 2005; International Society of Horticultural Science (ISHS)(693):727-32.

24. Ketterings QM, Coe R, van Noordwijk M, Ambagau Y, Palm CA. Reducing uncertainty in the use of allometric biomass equations for predicting above-ground tree biomass in mixed secondary forests. For Ecol Manag. 2001;146(1-3):199-209. doi:10.1016/ s0378-1127(00)00460-6.

25. Bombelli A, Avitabile V, Balzter H, Marchesini LB, Bernoux M, Brady $\mathrm{M}$ et al. Biomass-assessment of the status of the development of the standards for the terrestrial essential climate variables: Biomass 2009 Contract No.: GTOS 67.

26. Shvidenko A, Schepaschenko D, Nilsson S, Bouloui Y. Semiempirical models for assessing biological productivity of northern Eurasian forests. Ecol Model. 2007;204(1-2):163-79. doi:10. 1016/j.ecolmodel.2006.12.040.

27. West PW, Wells KF, Cameron DM, Rance SJ, Turnbull CRA, Beadle CL. Predicting tree diameter and height from aboveground biomass for four eucalypt species. Trees-Structure and Function. 1991;5(1):30-5.

28. Saint-André L, Mbou A, Mabiala A, Mouvondy W, Jourdan C, Roupsard O, et al. Age-related equations for above- and belowground biomass of a hybrid in Congo. For Ecol Manag. 2005;205(1-3):199-214. doi:10.1016/j.foreco.2004.10.006.

29. Muukkonen P. Generalized allometric volume and biomass equations for some tree species in Europe. Eur J For Res. 2007;126(2): 157-66. doi:10.1007/s10342-007-0168-4.

30. Návar J. Biomass component equations for Latin American species and groups of species. Ann For Sci. 2009;66(2):208. doi:10. 1051/forest/2009001. 
31. Keith H, Barrett D, Keenan R. Review Allometric Relationships for Estimating Woody Biomass: National Carbon Accounting System, Australian Greenhouse Office 2000.

32. Chave J, Andalo C, Brown S, Cairns M, Chambers J, Eamus D, et al. Tree allometry and improved estimation of carbon stocks and balance in tropical forests. Oecologia. 2005;145(1):87-99. doi:10. 1007/s00442-005-0100-x.

33. Feldpausch TR, Banin L, Phillips OL, Baker TR, Lewis SL, Quesada CA, et al. Height-diameter allometry of tropical forest trees. Biogeosciences. 2011;8(5):1081-106. doi:10.5194/bg-81081-2011.

34. Chave J, Condit R, Aguilar S, Hernandez A, Lao S, Perez R. Error propagation and scaling for tropical forest biomass estimates. Philos Trans R Soc Lond B Biol Sci. 2004;359(1443):409-20.

35. Buvaneswaran C, George M, Perez D, Kanninen M. Biomass of teak plantations in Tamil Nadu, India and Costa Rica compared. J Trop For Sci. 2006;18:195-7.

36. Duncanson L, Rourke O, Dubayah R. Small sample sizes yield biased allometric equations in temperate forests. Sci Rep. 2015;5. 10.1038/srep17153.

37. Henry M. Carbon stocks and dynamics in Sub-Saharian Africa [Doctoral Thesis]: Università degli studi della Tuscia - Viterbo; 2010.

38. AfriTRON. African Tropical Rainforest Observation Network (AfriTRON). University of Leeds. 2002. http://www.afritron.org/ en. 2016.

39. RAINFOR. The Amazon Forest Inventory Network. University of Leeds. 2000. http://www.rainfor.org/. 2016.

40. ForestPlots. ForestPlots.NET database. University of Leeds. 2009. http://www.forestplots.net/. 2016.

41. CTFS-ForestGEO. Smithsonian Tropical Research Institute - The Center for Tropical Forest Science and Forest Global Earth Observatories (CTFS-ForestGEO) database. Smithsonian Tropical Research Institute. 1980. http://www.ctfs.si.edu/. 2016.

42. Zianis D, Muukkonen P, Mäkipää R, Mencuccini M. Biomass and stem volume equations for tree species in Europe. Silva Fennica Monographs. 2005;4(Monographs 4):1-63.

43. Henry M, Picard N, Trotta C, Manlay RJ, Valentini R, Bernoux M, et al. Estimating tree biomass of sub-Saharan African forests: a review of available allometric equations. Silva Fennica. 2011;45(3B):477-569.

44. Yu Y, Saatchi S. Sensitivity of L-band SAR backscatter to aboveground biomass of global forests. Remote Sens. 2016;8(6):522.

45. Lillesand TM, Kiefer RW, Chipman JW. Remote sensing and image interpretation. Ed. 6th ed. Hoboken, NJ: Wiley; 2007.

46. Foody GM, Cutler ME, McMorrow J, Pelz D, Tangki H, Boyd DS, et al. Mapping the biomass of Bornean tropical rain forest from remotely sensed data. Glob Ecol Biogeogr. 2001;10(4): 379-87. doi:10.1046/j.1466-822X.2001.00248.x.

47. Kattenborn T, Maack J, Faßnacht F, Enßle F, Ermert J, Koch B. Mapping forest biomass from space-fusion of hyperspectral EO1-hyperion data and Tandem-X and WorldView-2 canopy height models. Int J Appl Earth Obs Geoinf. 2015;35:359-67.

48. Laurin GV, Chen Q, Lindsell JA, Coomes DA, Del Frate F, Guerriero L, et al. Above ground biomass estimation in an African tropical forest with lidar and hyperspectral data. ISPRS J Photogramm Remote Sens. 2014;89:49-58.

49. Avitabile V, Baccini A, Friedl MA, Schmullius C. Capabilities and limitations of Landsat and land cover data for aboveground woody biomass estimation of Uganda. Remote Sens Environ. 2011; doi: 10.1016/j.rse.2011.10.012

50. Nichol JE, Sarker MLR. Improved biomass estimation using the texture parameters of two high-resolution optical sensors. IEEE Transactions on Geoscience \& Remote Sensing. 2011;49(3):930 48. doi:10.1109/tgrs.2010.2068574.
51. Los SO, Pollack NH, Parris MT, Collatz GJ, Tucker CJ, Sellers PJ, et al. A global 9-yr biophysical land surface Dataset from NOAA AVHRR data. J Hydrometeorol. 2000;1(2):183-99. doi:10.1175/ 1525-7541(2000)001<0183:agybls>2.0.co;2.

52. Roy DP, Ju J, Kline K, Scaramuzza PL, Kovalskyy V, Hansen M, et al. Web-enabled Landsat data (WELD): Landsat ETM+ composited mosaics of the conterminous United States. Remote Sens Environ. 2010;114(1):35-49. doi:10.1016/j.rse.2009.08.011.

53.• Hansen MC, Potapov PV, Moore R, Hancher M, Turubanova SA, Tyukavina A, et al. High-resolution global maps of 21st-century forest cover change. Science. 2013;342(6160):850-3. doi:10. $1126 /$ science. 1244693 . This paper presents $30 \mathrm{~m}$ resolution global forest extent, loss, and gain for a 12-year period.

54. Moore R, Hansen M, editors. Google Earth Engine: a new cloudcomputing platform for global-scale earth observation data and analysis. AGU Fall Meeting Abstracts; 2011.

55. Schlerf M, Atzberger C, Hill J. Remote sensing of forest biophysical variables using HyMap imaging spectrometer data. Remote Sens Environ. 2005;95(2):177-94. doi:10.1016/j.rse.2004.12. 016.

56. Darvishzadeh R, Skidmore A, Atzberger C, van Wieren S. Estimation of vegetation LAI from hyperspectral reflectance data: effects of soil type and plant architecture. Int J Appl Earth Obs Geoinf. 2008;10(3):358-73. doi:10.1016/j.jag.2008.02.005.

57. Huber S, Kneubühler M, Psomas A, Itten K, Zimmermann NE. Estimating foliar biochemistry from hyperspectral data in mixed forest canopy. For Ecol Manag. 2008;256(3):491-501. doi:10. 1016/j.foreco.2008.05.011.

58. le Maire G, François C, Soudani K, Berveiller D, Pontailler JY, Bréda $\mathrm{N}$, et al. Calibration and validation of hyperspectral indices for the estimation of broadleaved forest leaf chlorophyll content, leaf mass per area, leaf area index and leaf canopy biomass. Remote Sens Environ. 2008;112(10):3846-64. doi:10.1016/j.rse. 2008.06.005.

59. Schlerf M. Determination of structural and chemical forest attributes using hyperspectral remote sensing data - case studies in Norway spruce forests: PhD Thesis, University of Trier. Available at http://ubt.opus.hbz-nrw.de/volltexte/2006/369; 2006.

60. Swatantran A, Dubayah R, Roberts D, Hofton M, Blair JB. Mapping biomass and stress in the Sierra Nevada using lidar and hyperspectral data fusion. Remote Sens Environ. 2011;115(11):2917-30. doi:10.1016/j.rse.2010.08.027.

61. Lucas RM, Lee AC, Bunting PJ. Retrieving forest biomass through integration of CASI and LiDAR data. Int J Remote Sens. 2008;29(5):1553-77. doi:10.1080/01431160701736497.

62. Kellndorfer J, Walker W, LaPoint L, Bishop J, Cormier T, Fiske G et al. NACP aboveground biomass and carbon baseline data (NBCD 2000), USA, 2000. Data set ORNL DAAC, Oak Ridge, Tennessee[Online] Available at daac ornl gov. 2011.

63. Rodriguez-Veiga P, Saatchi S, Tansey K, Balzter H. Magnitude, spatial distribution and uncertainty of forest biomass stocks in Mexico. Remote Sens Environ. 2016;183:265-81. doi:10.1016/j. rse.2016.06.004.

64. Khalefa E, Smit IP, Nickless A, Archibald S, Comber A, Balzter $H$. Retrieval of savanna vegetation canopy height from ICESatGLAS spaceborne LiDAR with terrain correction. Geoscience and Remote Sensing Letters, IEEE. 2013;10(6):1439-43.

65. Lefsky MA, Keller M, Pang Y, De Camargo PB, Hunter MO. Revised method for forest canopy height estimation from geoscience laser altimeter system waveforms. J Appl Remote Sens. 2007;1(013537):013537.

66. Sun G, Ranson KJ, Kimes DS, Blair JB, Kovacs K. Forest vertical structure from GLAS: an evaluation using LVIS and SRTM data. Remote Sens Environ. 2008;112(1):107-17. doi:10.1016/j.rse. 2006.09.036 
67. Balzter H, Luckman A, Skinner L, Rowland C, Dawson T. Observations of forest stand top height and mean height from interferometric SAR and LiDAR over a conifer plantation at Thetford Forest. UK International Journal of Remote Sensing. 2007;28(6):1173-97. doi:10.1080/01431160600904998.

68. Balzter H, Rowland CS, Saich P. Forest canopy height and carbon estimation at Monks Wood National Nature Reserve, UK, using dual-wavelength SAR interferometry. Remote Sens Environ. 2007;108(3):224-39. doi:10.1016/j.rse.2006.11.014.

69. Hinsley SA, Hill RA, Bellamy PE, Balzter H. The application of lidar in woodland bird ecology: climate, canopy structure, and habitat quality. Photogramm Eng Remote Sens. 2006;72(12): 1399-406.

70. Bradbury RB, Hill RA, Mason DC, Hinsley SA, Wilson JD, Balzter $\mathrm{H}$, et al. Modelling relationships between birds and vegetation structure using airborne LiDAR data: a review with case studies from agricultural and woodland environments. Ibis. 2005;147(3):443-52. doi:10.1111/j.1474-919x.2005.00438.x.

71. Drake JB, Dubayah RO, Knox RG, Clark DB, Blair JB. Sensitivity of large-footprint lidar to canopy structure and biomass in a neotropical rainforest. Remote Sens Environ. 2002;81(2-3): 378-92. doi:10.1016/s0034-4257(02)00013-5.

72.• Liu YY, van Dijk AIJM, de Jeu RAM, Canadell JG, McCabe MF, Evans JP, et al. Recent reversal in loss of global terrestrial biomass. Nature Clim Change. 2015;5(5):470-4. doi:10.1038/ nclimate2581. http://www.nature.com/nclimate/journal/vaop/ ncurrent/abs/nclimate2581.html\#supplementary-information. This paper estimates global AGB trends during the past two decades (1993-2012) from satellite passive microwave observations.

73. Zhang N, Shi J, Sun G, Guo Z, Chai L, editors. Assessment of boreal forest biomass using L-band radiometer SMOS data. Geoscience and Remote Sensing Symposium (IGARSS), 2011 I.E. International; 2011 24-29 July 2011.

74. Hein A. Processing of SAR data. Fundamentals, Signal Processing, Interferometry. Springer; 2004. doi:10.1007/978-3662-09457-0.

75. Freeman A, Durden SL. A three-component scattering model for polarimetric SAR data. Geoscience and Remote Sensing, IEEE Transactions on. 1998;36(3):963-73.

76. Mitchard ETA, Saatchi SS, Lewis SL, Feldpausch TR, Woodhouse IH, Sonké B, et al. Measuring biomass changes due to woody encroachment and deforestation/degradation in a forest-savanna boundary region of central Africa using multitemporal L-band radar backscatter. Remote Sens Environ. 2011;115(11):2861-73. doi:10.1016/j.rse.2010.02.022.

77. Le Toan T, Quegan S, Woodward I, Lomas M, Delbart N, Picard G. Relating radar remote sensing of biomass to modelling of forest carbon budgets. Clim Chang. 2004;67:379-402.

78. Wagner W, Luckman A, Vietmeier J, Tansey K, Balzter H, Schmullius C, et al. Large-scale mapping of boreal forest in SIBERIA using ERS tandem coherence and JERS backscatter data. Remote Sens Environ. 2003;85(2):125-44. doi:10.1016/ s0034-4257(02)00198-0.

79. Mitchard ETA, Saatchi SS, Woodhouse IH, Nangendo G, Ribeiro NS, Williams M, et al. Using satellite radar backscatter to predict above-ground woody biomass: a consistent relationship across four different African landscapes. Geophys Res Lett. 2009;36(23):L23401. doi:10.1029/2009g1040692.

80. Lucas R, Armston J, Fairfax R, Fensham R, Accad A, Carreiras J, et al. An evaluation of the ALOS PALSAR L-band backscatterabove ground biomass relationship Queensland, Australia: impacts of surface moisture condition and vegetation structure. Selected Topics in Applied Earth Observations and Remote Sensing, IEEE Journal of. 2010;3(4):576-93.
81. Englhart S, Keuck V, Siegert F. Aboveground biomass retrieval in tropical forests - the potential of combined X- and L-band SAR data use. Remote Sens Environ. 2011;115:1260-71. doi:10.1016/ j.rse.2011.01.008.

82. Imhoff ML. Radar backscatter and biomass saturation: ramifications for global biomass inventory. Geoscience and Remote Sensing, IEEE Transactions on. 1995;33(2):511-8.

83. Carreiras JMB, Vasconcelos MJ, Lucas RM. Understanding the relationship between aboveground biomass and ALOS PALSAR data in the forests of Guinea-Bissau (West Africa). Remote Sens Environ. 2012;121:426-42. doi:10.1016/j.rse.2012.02.012.

84. Naesset E. Airborne laser scanning as a method in operational forest inventory: status of accuracy assessments accomplished in Scandinavia. Scand J For Res. 2007;22(5):433-42. doi:10.1080/ 02827580701672147.

85. Dobson MC, Ulaby FT, LeToan T, Beaudoin A, Kasischke ES, Christensen N. Dependence of radar backscatter on coniferous forest biomass. Geoscience and Remote Sensing, IEEE Transactions on. 1992;30(2):412-5. doi:10.1109/36.134090.

86. Le Toan T, Quegan S, Davidson MWJ, Balzter H, Paillou P, Papathanassiou K, et al. The BIOMASS mission: mapping global forest biomass to better understand the terrestrial carbon cycle. Remote Sens Environ. 2011;115(11):2850-60. doi:10.1016/j.rse. 2011.03.020.

87. Breiman L. Statistical modeling: the two cultures (with comments and a rejoinder by the author). Stat Sci. 2001;16(3):199-231.

88. Evans JS, Cushman SA. Gradient modeling of conifer species using random forests. Landsc Ecol. 2009;24(5):673-83.

89. Tsui OW, Coops NC, Wulder MA, Marshall PL. Integrating airborne LiDAR and space-borne radar via multivariate kriging to estimate above-ground biomass. Remote Sens Environ. 2013;139(0):340-52. doi:10.1016/j.rse.2013.08.012.

90. McRoberts RE, Tomppo EO, Finley AO, Heikkinen J. Estimating areal means and variances of forest attributes using the k-nearest neighbors technique and satellite imagery. Remote Sens Environ. 2007;111(4):466-80. doi:10.1016/j.rse.2007.04.002.

91. Del Frate F, Solimini D. On neural network algorithms for retrieving forest biomass from SAR data. Geoscience and Remote Sensing, IEEE Transactions on. 2004;42(1):24-34. doi:10.1109/ TGRS.2003.817220.

92. Ruesch A, Gibbs H. New IPCC tier-1 global biomass carbon map for the year 2000. Oak Ridge, Tennessee: Available online from the Carbon Dioxide Information Analysis Center [http:// cdiacornlgov], Oak Ridge National Laboratory; 2008.

93. Kindermann GE, McCallum I, Fritz S, Obersteiner M. A global forest growing stock, biomass and carbon map based on FAO statistics. Silva Fennica. 2008;42(3):387.

94. Avitabile V, Herold M, Lewis S, Phillips O, AguilarAmuchastegui N, Asner G et al., editors. Comparative analysis and fusion for improved global biomass mapping. Book of abstracts of the International Conference Global Vegetation Monitoring and Modeling (GV2M); 2014.

95. Avitabile V, Herold M, Heuvelink G, Lewis SL, Phillips OL, Asner GP et al. An integrated pan-tropical biomass map using multiple reference datasets. Global change biology. 2016. This paper presents a fusion of previous pan-tropical maps.

96. Santoro M, Beaudoin A, Beer C, Cartus O, Fransson JE, Hall RJ, et al. Forest growing stock volume of the northern hemisphere: spatially explicit estimates for 2010 derived from Envisat ASAR. Remote Sens Environ. 2015;168:316-34.

97. Hu T, Su Y, Xue B, Liu J, Zhao X, Fang J, et al. Mapping global forest aboveground biomass with spaceborne LiDAR, optical imagery, and forest inventory data. Remote Sens. 2016;8(7):565.

98. Gallaun H, Zanchi G, Nabuurs G-J, Hengeveld G, Schardt M, Verkerk PJ. EU-wide maps of growing stock and above-ground biomass in forests based on remote sensing and field 
measurements. For Ecol Manag. 2010;260(3):252-61. doi:10. 1016/j.foreco.2009.10.011.

99. Yin G, Zhang Y, Sun Y, Wang T, Zeng Z, Piao S. MODIS based estimation of forest aboveground biomass in China. PLoS One. 2015;10(6): 0130143

100. Du L, Zhou T, Zou Z, Zhao X, Huang K, Wu H. Mapping forest biomass using remote sensing and national forest inventory in China. Forests. 2014;5(6):1267-83.

101. Beaudoin A, Bernier P, Guindon L, Villemaire P, Guo X, Stinson $\mathrm{G}$, et al. Mapping attributes of Canada's forests at moderate resolution through $\mathrm{k}$ NN and MODIS imagery. Can J For Res. 2014;44(5):521-32.

102. Houghton R, Butman D, Bunn AG, Krankina O, Schlesinger P, Stone T. Mapping Russian forest biomass with data from satellites and forest inventories. Environ Res Lett. 2007;2(4):045032.

103. Saatchi S, Malhi Y, Zutta B, Buermann W, Anderson LO, Araujo AM, et al. Mapping landscape scale variations of forest structure, biomass, and productivity in Amazonia. Biogeosciences Discuss. 2009;6(3):5461-505. doi:10.5194/bgd-6-5461-2009.

104. Saatchi SS, Houghton R, Dos Santos AR, Soares J, Yu Y. Distribution of aboveground live biomass in the Amazon basin. Glob Chang Biol. 2007;13(4):816-37.

105. Asner GP, Knapp DE, Martin RE, Tupayachi R, Anderson CB, Mascaro J, et al. Targeted carbon conservation at national scales with high-resolution monitoring. Proc Natl Acad Sci. 2014;111(47):E5016-E22.

106. Asner GP, Mascaro J, Anderson C, Knapp DE, Martin RE, Kennedy-Bowdoin $\mathrm{T}$ et al. High-fidelity national carbon mapping for resource management and REDD+. Carbon balance and management. 2013;8(7)

107. Avtar R, Suzuki R, Takeuchi W, Sawada H. PALSAR 50 m mosaic data based national level biomass estimation in Cambodia for implementation of REDD+ mechanism. PLoS One. 2013;8(10): e74807.

108. Anaya JA, Chuvieco E, Palacios-Orueta A. Aboveground biomass assessment in Colombia: a remote sensing approach. For Ecol Manag. 2009;257(4):1237-46.

109. Perrin IF, Nicolas B, Jean-Stéphane B, Nicolas B, Valéry G, Bruno $\mathrm{H}$, et al. Regional scale rain-forest height mapping using regression-kriging of spaceborne and airborne LiDAR data: application on French Guiana. Remote Sens. 2016;8(3):240. doi:10. $3390 /$ rs8030240.

110. Hudak AT, Lefsky MA, Cohen WB, Berterretche M. Integration of lidar and Landsat ETM+ data for estimating and mapping forest canopy height. Remote Sens Environ. 2002;82(2-3):397-416. doi:10.1016/S0034-4257(02)00056-1.

111. Lu D, Chen Q, Wang G, Moran E, Batistella M, Zhang M, et al. Aboveground forest biomass estimation with Landsat and LiDAR data and uncertainty analysis of the estimates. International Journal of Forestry Research. 2012;2012:16. doi:10.1155/2012/ 436537.

112. Benítez F, Anderson L, Formaggio A. Evaluation of geostatistical techniques to estimate the spatial distribution of aboveground biomass in the Amazon rainforest using high-resolution remote sensing data. Acta Amazon. 2016;46:151-60.

113. Maack J, Kattenborn T, Ewald Fassnacht F, Enssle F, Hernández Palma J, Corvalán Vera P et al. Modeling forest biomass using Very-High-Resolution data-Combining textural, spectral and photogrammetric predictors derived from spaceborne stereo images. 2015.

114. Neigh C, Masek J, Bourget P, Cook B, Huang C, Rishmawi K, et al. Deciphering the precision of stereo IKONOS canopy height models for US forests with G-LiHT airborne LiDAR. Remote Sens. 2014;6(3):1762.

115. Persson H, Wallerman J, Olsson H, Fransson JES. Estimating forest biomass and height using optical stereo satellite data and a
DTM from laser scanning data. Can J Remote Sens. 2013;39(3): 251-62. doi:10.5589/m13-032.

116. St-Onge B, Hu Y, Vega C. Mapping the height and above-ground biomass of a mixed forest using lidar and stereo Ikonos images. Int J Remote Sens. 2008;29(5):1277-94. doi:10.1080/ 01431160701736505.

117. Thenkabail PS, Enclona EA, Ashton MS, Legg C, De Dieu MJ. Hyperion, IKONOS, ALI, and ETM+ sensors in the study of African rainforests. Remote Sens Environ. 2004;90(1):23-43. doi:10.1016/j.rse.2003.11.018.

118. Clark ML, Roberts DA, Ewel JJ, Clark DB. Estimation of tropical rain forest aboveground biomass with small-footprint lidar and hyperspectral sensors. Remote Sens Environ. 2011;115(11): 2931-42. doi:10.1016/j.rse.2010.08.029.

119. Anderson JE, Plourde LC, Martin ME, Braswell BH, Smith ML, Dubayah RO, et al. Integrating waveform lidar with hyperspectral imagery for inventory of a northern temperate forest. Remote Sens Environ. 2008;112(4):1856-70. doi:10.1016/j.rse.2007.09.009.

120. Zebker HA, Villasenor J. Decorrelation in interferometric radar echoes. Geoscience and Remote Sensing, IEEE Transactions on. 1992;30(5):950-9.

121. Tansey KJ, Luckman AJ, Skinner L, Balzter H, Strozzi T, Wagner W. Classification of forest volume resources using ERS tandem coherence and JERS backscatter data. Int J Remote Sens. 2004;25(4):751-68.

122. Cloude SR, Woodhouse IH, Suarez JC. Polarimetry and Polarimetric Interferometry for Forestry Applications: Final Report2011 2011 Contract No.: JAXA-SP-11-007E.

123. Papathanassiou KP, Kugler F, Lee S, Marotti L, Hajnsek I. Recent advances in polarimetric SAR interferometry for forest parameter estimation. RADAR Conference, 2008 IEEE. 2008:1-6. doi:10. 1109/RADAR.2008.4720870.

124. Cloude SR, Papathanassiou KP. Polarimetric SAR interferometry. Geoscience and Remote Sensing, IEEE Transactions on. 1998;36(5):1551-65.

125. Cloude SR. Polarization coherence tomography. Radio Sci. 2006;41(4):RS4017. doi:10.1029/2005RS003436.

126. Phillips SJ, Anderson RP, Schapire RE. Maximum entropy modeling of species geographic distributions. Ecol Model. 2006;190(34):231-59. doi:10.1016/j.ecolmodel.2005.03.026.

127. Phillips SJ, Dud M, \#237, Schapire RE. A maximum entropy approach to species distribution modeling. Proceedings of the twenty-first international conference on Machine learning; Banff, Alberta, Canada. 1015412: ACM; 2004. p. 83.

128. Mitchard E, Saatchi S, Baccini A, Asner G, Goetz S, Harris N, et al. Uncertainty in the spatial distribution of tropical forest biomass: a comparison of pan-tropical maps. Carbon balance and management. 2013;8(1):10.

129. Mitchard ETA, Feldpausch TR, Brienen RJW, Lopez-Gonzalez G, Monteagudo A, Baker TR, et al. Markedly divergent estimates of Amazon forest carbon density from ground plots and satellites. Glob Ecol Biogeogr. 2014;23(8):935-46. doi:10.1111/geb.12168.

130. Carreiras J, Melo J, Vasconcelos M. Estimating the above-ground biomass in Miombo savanna woodlands (Mozambique, East Africa) using L-band synthetic aperture radar data. Remote Sens. 2013;5(4):1524-48.

131. Saatchi S, Mascaro J, Xu L, Keller M, Yang Y, Duffy P, et al. Seeing the forest beyond the trees. Glob Ecol Biogeogr. 2015;24(5):606-10. doi:10.1111/geb.12256.

132. FAO. Global forest resources assessment 2005: Food and Agriculture Organization of the United Nations2005.

133. FAO. Global forest resources assessment 2010: Food and Agriculture Organization of the United Nations2010 2010.

134. FAO. Global Forest Resources Assessments (FRA). Food and Agriculture Organization of the United Nations. 2012. http:// www.fao.org/forestry/fra/en/. Accessed May 20122012. 
135. Waggoner PE. Forest Inventories: Discrepancies and Uncertainties. Washington DC: Resources For the Future2009 August 2009.

136. Houghton RA. Aboveground forest biomass and the global carbon balance. Glob Chang Biol. 2005;11(6):945-58. doi:10.1111/j. 1365-2486.2005.00955.x.

137. Bartholomé E, Belward A. GLC2000: a new approach to global land cover mapping from Earth observation data. Int $\mathrm{J}$ Remote Sens. 2005;26(9):1959-77.

138. Vittucci C, Ferrazzoli P, Kerr Y, Richaume P, Guerriero L, Rahmoune R, et al. SMOS retrieval over forests: exploitation of optical depth and tests of soil moisture estimates. Remote Sens Environ. 2016;180:115-27. doi:10.1016/j.rse.2016.03.004.

139.• Pan Y, Birdsey RA, Fang J, Houghton R, Kauppi PE, Kurz WA, et al. A large and persistent carbon sink in the world's forests. Science. 2011;333(6045):988-93. This paper presents a bottom-up estimation of carbon stocks and fluxes for the world's forests based on inventory data and long-term field observations.

140. Schepaschenko D, Fritz S, McCallum I, Shvidenko A, Perger C, Schill C, et al. A platform to visualize, analyze and improve biomass datasets: http://www.biomass.geo-wiki.org. Folia Forestalia Pol Ser A. 2012;54:137-9.

141. CarbonMaps. Comparing Global Carbon Maps - Our Ecosystem. Ecometrica Ltd. 2014. https://carbonmaps.ourecosystem.com/. 2014.

142. GFW. Global Forest Watch. World Resources Institute. 2011. 2016.

143. Awadallah MS, Abbott AL, Thomas VA, Wynne RH, Nelson RF. Estimating Forest Canopy Height using Photon-counting Laser Altimetry. Silvilaser; 2013.

144. Gwenzi D, Lefsky M. Prospects of photon counting lidar for savanna ecosystem structural studies. The International Archives of Photogrammetry, Remote Sensing and Spatial Information Sciences. 2014;40(1):141.

145. Montesano PM, Rosette J, Sun G, North P, Nelson RF, Dubayah RO, et al. The uncertainty of biomass estimates from modeled ICESat-2 returns across a boreal forest gradient. Remote Sens Environ. 2015;158:95-109. doi:10.1016/j.rse. 2014.10.029.
146. Dubayah R, Goetz S, Blair J, Fatoyinbo T, Hansen M, Healey S et al., editors. The global ecosystem dynamics investigation. AGU Fall Meeting Abstracts; 2014.

147. Coyle DB, Stysley PR, Poulios D, Clarke GB, Kay RB, editors. Laser transmitter development for NASA's Global Ecosystem Dynamics Investigation (GEDI) lidar. SPIE Optical Engineering + Applications: International Society for Optics and Photonics; 2015 .

148. Asai K, Sato R, Kobayashi T, Imai T, editors. Multi-footprint Observation LiDAR and Imager (MOLI) on the ISS-JEM Mission. Geoscience and Remote Sensing Symposium; 2014.

149. Rodriguez-Veiga P, Saatchi S, Wheeler J, Tansey K, Balzter H. Methodology for Regional to Global Mapping of Above Ground Forest Biomass: Integrating Forest Allometry, Ground Plots, and Satellite Observations. In: Balzter H, editor. Earth Observation for Land and Emergency Monitoring - Innovative concepts for environmental monitoring from space. Chichester: Wiley-Blackwell; 2017.

150. Ningthoujam R, Balzter H, Tansey K, Morrison K, Johnson S, Gerard F, et al. Airborne S-band SAR for forest biophysical retrieval in temperate mixed forests of the UK. Remote Sens. 2016;8(7):609

151. Hélière F, Fois F, Lin C, Scipal K, Arcioni M, Bensi P, et al. Biomass: new mission selected as the 7th ESA Earth Explorer Mission. Towards Horizon. 2013;2020:89-98.

152. Mitchard ETA, Saatchi SS, Woodhouse IH, Nangendo G, Ribeiro NS, Williams M, et al. Using satellite radar backscatter to predict above-ground woody biomass: a consistent relationship across four different African landscapes. Geophys Res Lett. 2009;36(23):L23401. doi:10.1029/2009g1040692.

153. Schmullius C, Seifert FM, Thiel C, Pathe C, Matejka E, Quegan S et al., editors. DUE GlobBiomass - Estimates of Biomass on a Global Scale. ISRSE; 2015 11-15 May 2015; Berlin.

154. Balzter H, Rodriguez-Veiga P, Tansey K, Quegan S, Carreiras J, Persson HJ et al. GLOBBIOMASS Regional Case Studies Preparing the Ground for Global Forest Biomass Mapping. ESA Living Planet Symposium; 2016; Prague.

155. Cartus O, Santoro M, editors. Multi-scale Mapping of Forest Growing Stock Volume using ENVISAT ASAR, ALOS PALSAR, Landsat, and ICESAT GLAS. ESA Living Planet Symposium; 2016; Prague. 